\title{
PENGARUH PHONOPHORESIS UNTUK MENURUNKAN NYERI PASIEN OSTEOARTHRITIS LUTUT
}

\author{
Saifudin Zuhri*1, Budi Utomo ${ }^{2}$ \\ Poltekkes Kemenkes Surakarta Jurusan Fisioterapi
}

\begin{abstract}
Background: In everyday life activities human beings need prime conditions to create functional motion. One factor that interferes with functional motion is pain. The goal of physiotherapy for people with pain is to relieve pain. Many of the physiotherapy modalities recommended for reducing pain include phonophoresis. But the phonophoresis modality has not been widely implemented in Indonesia. Objective: To determine the effect of phonophoresis on reducing knee pain in patients with knee osteoarthritis. Method: This study was a pure experiment with a pre-test and post-test with control group design. The study subjects were patients with knee osteoarthritis who met the inclusion and exclusion criteria. From the number of patients who came to the physiotherapy polyclinic of Dr Moewardi Hospital Surakarta, they would be randomized to the experimental group and the control group. The experimental group will get standard therapy at Dr Moewardi Hospital Surakarta plus phonophoresis, while the control group only gets standard therapy from the hospital. The independent variable is the administration of phonophoresis and the dependent variable is a decrease in knee pain. Statistical analysis using t-test. Results: Of Phonophoresis and standard therapy can reduce knee pain. More pain occurs in phonophoresis. Conclusion: Phonophoresis can be selected as a therapy to reduce pain in people with osteoarthritis
\end{abstract}

Keywords: Phonophoresis, Knee Osteoarthritis, Visual Analogue Scale

\section{PENDAHULUAN}

Sejalan dengan perkembangan IPTEK, teruatama di bidang pangan dan fasilitas lain, maka angka harapan hidup makin meningkat. Di sisi lain penyakit degeneratif seperti osteoarthritis dan didukung gaya hidup yang tidak memperhatikan kesehatan, maka penyakit tersebut potensial juga meningkat. Otopsi menunjukkan bahwa perubahan degeneratif dimulai pada dekade ke dua. Pada usia 40 tahun, $90 \%$ orang mengalami perubahan pada sendi penumpu berat badan, walau belum ada gejala klinik. Manifestasi penyakit secara gambaran radiologik meningkat progresif dengan usia (Tulaar, 2006).
Prevalensi osteoarthritis berkorelasi dengan usia. Pada umur di bawah 50 tahun, laki-laki lebih cenderung terkena osteoarthritis daripada wanita, tapi di atas 50 tahun wanita lebih sering menderita osteoarthritis (AF, 2006). Pada suatu survei radiografi dilaporkan osteoarthritis lutut didapatkan pada usia 45 -64 tahun hanya $25-30 \%$ terkena osteoarthritis, sedangkan pada usia > 65 tahun angka kejadian osteoarthritis sebesar $60 \%$ dan pada usia > 75 tahun angka kejadiannya lebih dari $80 \%$ (Furqan, 2005).

Di poliklinik rematologi RSUP dr. Kariadi Semarang, kurun waktu 19911993, tercatat penderita osteoartritis dengan persentase $63 \%$ dari seluruh 
penderita rematik yang ada, dan sebagian besar adalah osteoartritis sendi lutut (Parjoto, 2000).

Osteoartritis sendi lutut banyak dialami oleh manusia usia lanjut, terutama wanita (Kusworini, 2000). Dari 74 kasus osteoartritis lutut di RS St. Carolus Jakarta, tercatat 63 kasus adalah wanita (Reksoprodjo, 1990). Usia merupakan faktor resiko tertinggi untuk osteoartritis lutut. Survei yang pernah dilakukan menunjukkan bahwa wanita berusia kurang dari 45 tahun hanya $2 \%$ dinyatakan sebagai penderita osteoarthritis lutut, dan pada kelompok usia 45 sampai dengan 64 tahun meningkat menjadi 30 $\%$, sedangkan mereka yang berusia di atas 65 tahun mempunyai kecenderungan mencapai $68 \%$ (Brandt, 2000). Meskipun tidak juga bisa dipungkiri bahwa ada pula penderita osteoartritis yang berusia kurang dari 24 tahun (Sidharta, 1984).

Destruksi pada tulang yang berlanjut, akan menimbulkan rasa nyeri. Apabila nyeri timbul dalam pergerakan maka penderita akan membatasi pergerakan pada sendi lutut. Gerak terjadi karena kontraksi otot, sehingga membatasi gerakan pada sendi lutut sama artinya dengan membatasi kontraksi otot penggerak sendi lutut. Terbatasnya kontraksi otot akan berakibat menurunnya kekuatan otot $3 \%$ per minggu dan mengecilnya ukuran otot, terarah pada disuse atrophy (Maurer et all, 1999). Padahal otot merupakan stabilitas aktif pada persendian, sehingga keadaan ini akan berdampak pada berkurangnya stabilitas sendi dan kemampuan sendi untuk meredam beban. Dampak ini akan menibulkan rasa nyeri pada pergerakan. Demikianlah terjadi siklus antara rasa nyeri dan menurunnya kekuatan otot, dua hal yang merupakan faktor timbal balik, yang satu sama lain saling menunjang dalam memperberat kondisi.

Rasa nyeri dan instabilitas pada persendian, berdampak pada disabilitas penderita (Isbagio, 2001). Terjadi disabilitas / kecacatan secara kronis yang menurunkan produktifitas dan kualitas hidup penderita (Brandt, 2000), terutama akibat timbulnya rasa nyeri (Kasjmir, 2003).

Upaya untuk menghilangkan atau mengurangi nyeri, dapat dilakukan dengan phonophoresis yaitu transfer obat analgesik ke dalam jaringan dengan bantuan ultrasound. Modalitas fisioterapi ini sudah banyak direkomendasikan untuk mengurangi/menghilangkan nyeri tetapi belum tersosialisasikan secara intensif di lingkungan tenaga kesehatan terutama fisioterapi di Indonesia, apalagi tingkat aplikasiny, sehingga peneliti tertarik untuk melakukan penelitian, sehingga hasilnya dapat digunakan sebagai evaluasi dan saran aplikasi selanjutnya dalam menghadapi permasalahan nyeri.

\section{METODE PENELITIAN}

Penelitian yang dilakukan adalah penelitian eksperimen kuasi dengan metode pre test - post test design with control. Dalam penelitian ini, penulis mempergunakan data primer yaitu dengan mengukur pengurangan nyeri pada kelompok perlakuan (terapi standar dan phonophoresis) dan kelompok kontrol (terapi standar).

Penelitian dilakukan di Bagian Fisioterapi RSUD Dr. Moewardi Surakarta. Waktu penelitian pada bulan Oktober 2008. Populasi dari penelitian ini adalah pasien osteoarthritis yang datang di Bagian Fisioterapi RSUD Dr. Moewardi Surakarta dan subyek penelitian yang digunakan adalah pasien yang memenuhi 
kriteria inklusi dan eksklusi yang datang pada bulan Oktober 2008 dengan teknik Total Sampling. Randomisasi dilakukan untuk membagi sampel kedalam kelompok perlakuan atau kontrol.

Pengumpulan data dilakukan dengan mengukur nyeri sebelum dan sesudah dilakukan terapi pada kedua kelompok dengan menggunakan alat ukur Visual Analog Scale (VAS) .

Analisis nilai nyeri sebelum dan sesudah terapi pada masing-masing kelompok menggunakan paired $t$ test. Analisis penurunan nyeri antara kedua kelompok menggunakan independent $t$ test .

Phonophoresis merupakan transfer molekul ibuprofen 5\% ke dalam campuran gel ultrasound ke dalam jaringan secara topikal dengan bantuan ultrasound. Terapi standar merupakan terapi yang diberikan medis dan tindakan fisioterapi di RSUD Dr Moewardi Surakarta. Penurunan derajat nyeri lutut merupakan penurunan derajat nyeri sesuai skala nyeri yang dirasakan penderita osteoarthritis setelah diberikan terapi. Pengukuran skala nyeri menggunakan Visual Analog Scale (VAS). Skala data adalah numerik.

\section{HASIL PENELITIAN}

Sampel dalam penelitian ini adalah pasien osteoarthritis yang berobat atau berkunjung ke bagian fisioterapi RSUD Tabel 1. Karakteristik Subyek Penelitian
Variabel independen dalam penelitian ini adalah terapi standar dan phonophoresis. Variabel dependen dalam penelitian ini adalah nyeri lutut Pengukuran skala nyeri menggunakan Visual Analog Scale (VAS). Skala data adalah numerik.

Prosedur penelitian meliputi: (1) subyek penelitian yang memenuhi kriteria inklusi dan eksklusi dibagi dalam dua kelompok penelitian dengan cara randomisasi. Kelompok pertama mendapat terapi standar dan phonophoresis, kelompok kedua mendapat terapi standar, (2) pelaksanaan phonophoresis yaitu ultrasound dengan kandungan gel 5\% ibuprofen cream selama 5 menit, gelombang kontinyu, frekuensi $1 \mathrm{MHz}$ dan intensitas 1 watt $/ \mathrm{cm}^{2}$. Dilaksanakan $3 \mathrm{kali} /$ minggu selama 2 minggu, (3) Pelaksanaan terapi standar yaitu terapi yang diberikan medis dan tindakan fisioterapi selain phonophoresis.

Pengukuran nyeri dilakukan sebelum dan sesudah pemberian program terapi menggunakan Visual Analog Scale (VAS).

Dr. Moewardi Surakarta pada bulan Oktober tahun 2008.

\begin{tabular}{lcc}
\hline Karakteristik & Kelompok I & Kelompok II \\
\hline Jumlah sampel & 15 orang & 14 orang \\
\hline Umur & 50 tahun & 53 tahun \\
a. Minimal & 74 tahun & 72 tahun \\
b. Maksimal & 61,6 tahun & 60,7 tahun \\
c. Mean & 6,17 & 6,60 \\
d. SD &
\end{tabular}

Jenis Kelamin

a. Laki-laki

6 orang $(40 \%)$

7 orang $(50 \%)$ 


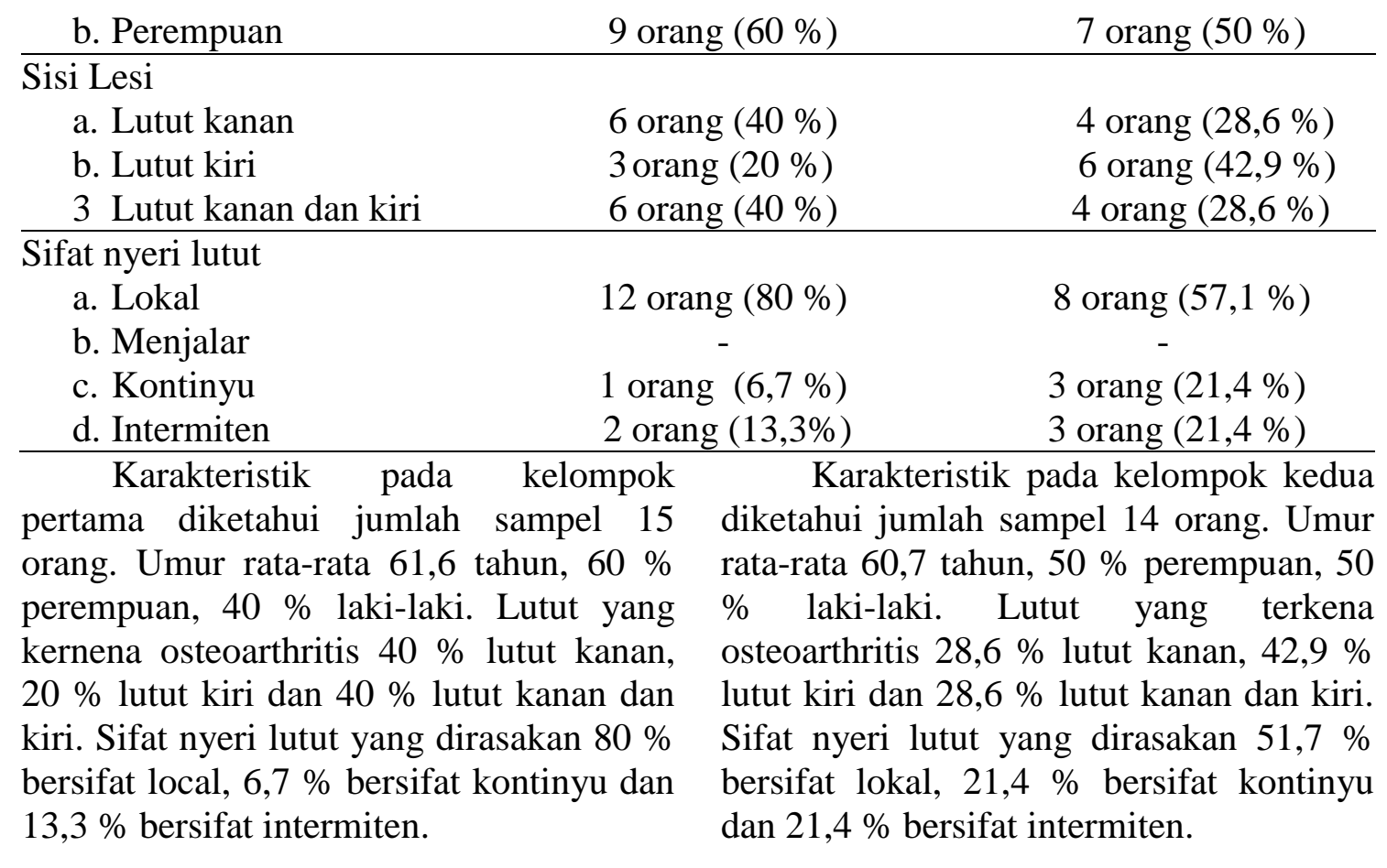

Tabel 2. Karakteristik Nilai Nyeri

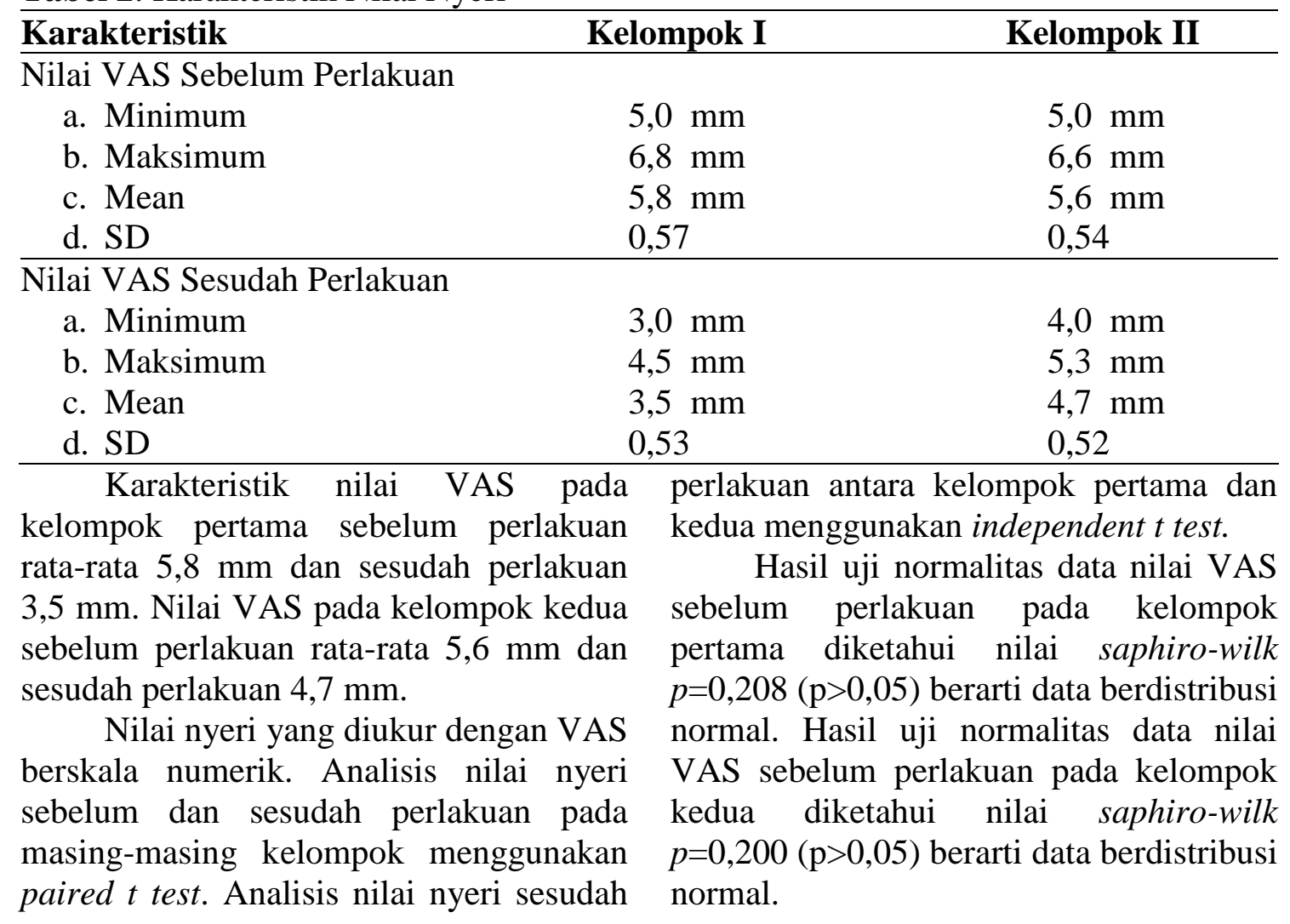


Hasil uji beda nilai VAS sebelum dan sesudah perlakuan pada kelompok pertama menggunakan paired $t$ test didapatkan hasil $\mathrm{p}=0,00(\mathrm{p}<0,05)$ berarti ada beda nilai VAS sebelum dan sesudah perlakuan. Besar penurunan nyeri adalah 2,3 $\mathrm{mm}$.

Hasil uji beda nilai VAS sebelum dan sesudah perlakuan pada kelompok kedua menggunakan paired $t$ test didapatkan hasil $p=0,00(\mathrm{p}<0,05)$ berarti ada beda nilai VAS sebelum dan sesudah perlakuan. Besar penurunan nyeri adalah $0,92 \mathrm{~mm}$.

Hasil uji beda rata-rata nilai VAS sebelum dan sesudah perlakuan antara kelompok pertama dan kedua menggunakan independent $t$ test didapatkan hasil $p=0,000(\mathrm{p}<0,05)$ berarti ada beda rata-rata nilai VAS sebelum dan sesudah perlakuan antara kelompok pertama dan kedua. Rata-rata penurunan nyeri pada kelompok pertama sebesar 2,3 $\mathrm{mm}$ dan kelompok kedua 0,92 $\mathrm{mm}$.

\section{PEMBAHASAN}

Kerusakan permukaan kartilago sendi lutut pada osteoarthritis lutut secara klinis berdampak mengakibatkan nyeri, kekakuan sendi dan keterbatasan gerak sendi terutama pada saat penumpuan berat badan. Tindakan terapi telah banyak pilihan baik terapi secara farmakologis maupun non farmakologis.

Penggunaan non steroid antiinflamatory drugs (NSAID) telah secara luas dipilih sebagai terapi simptomatik pada osteoartritis lutut. NSAID berpotensi menimbulkan efek negatif pada gastrointestinal. Program fisioterapi direkomendasikan sebagai terapi non farmakologis pada manajemen osteoartritis.
Teknologi fisioterapi untuk mengurangi nyeri telah banyak dikembangkan antara lain terapi panas, terapi dingin, terapi sinar dan beberapa terapi elektris. Tetapi itu hanya mempunyai efek superfisial, hanya dikulit atau jaringan subkutan.

Ultrasound merupakan teknologi fisioterapi yang mempunyai efek deep heating yang mampu meningkatkan temperatur $4-5{ }^{\circ} \mathrm{C}$ dan penetrasi mencapai $8 \mathrm{~cm}$. Phonophoresis merupakan pengembangan teknik terapi ultrasound yaitu dengan pemasukan obat kedalam jaringan perkutaneus.

Peningkatan temperatur jaringan pada pemberian ultrasound memiliki efek yang sangat penting, antara lain meningkatkan suplai darah regional dan meningkatkan extensibilitas jaringan lunak. Pemasukan ion obat spesifik secara transdermal pada phonophoresis seperti ibuprofen kream akan menghambat enzym inflamasi.

\section{KESIMPULAN DAN SARAN}

Berdasarkan hasil penelitian dan pembahasan maka dapat disimpulkan bahwa pemberian ultrasound maupun phopophoresis sebanyak 6 kali selama 2 minggu pada 29 pasien osteoarthritis yang ada di RSUD Dr. Moewardi Surakarta berpengaruh terhadap penurunan nyeri lutut.

Penurunan nyeri pada kelompok phonophoresis lebih banyak dibanding kelompok terapi standar, sehingga phopophoresis dapat digunakan sebagai terapi pilihan.

Sehingga peneliti memberikan saran untuk penelitian selanjutnya untuk menambahkan jumlah subyek penelitian agar hasilnya lebih dapat menggambarkan populasi, melakukan kontrol terhadap 
aktivitas subyek penelitian perlu dilakukan sehingga hasil penurunan nyeri dapat lebih optimal dan pemberian phonophoresis dalam terapi osteoarthritis lutut perlu dikembangkan dengan mempertimbangkan ukuran molekul obat, daya tahan obat terhadap panas dan vibrasi dari mesin ultrasound serta dosis pemberian.

\section{DAFTAR RUJUKAN}

Altman, R.D. 1991; Criteria for Clacification of Clinical Osteoarthritis; Journal of Rematologi, hal. 5 - 10.

Bare, A.C., McAnaw, M.B.B., Pritchard, A.D., et al 1996; Phonophoretic delivery of $10 \%$ hydrocortisone through the epidermis of humans as determined by serum cortisol concentrations. Physical Therapy, 76 (7), 756-749

Bland, John H. 1993; Mechanisms of Adaptation in the Joint; Crosbie, Jack and McConnel, Jenny; Key Issues in Musculoskeletal Physiotherapy; edisi ke-1, Butterworth-Heinemann Ltd, Oxford, hal. 88-110

Brandt, Kenneth 2000; Prinsip-prinsip Ilmu Penyakit Dalam; edisi ke-13, volume ke - 4, EGC, Jakarta, hal. $1886-1890$.

Byl, N.N. 1995; The use of ultrasound as an enhancer for transcutaneous drug delivery : Phonophoresis. Physical Therapy, 75 (6), 539-553.

Darmawan, John 1996; Penanganan dan Terapi Osteoartritis Lutut; Pendidikan Kedokteran Berkelanjutan (PKB) Uji Diri, Jakarta, hal. 1-14.

Furqan, H. Siddiqui, Osteoarthritis. $\mathrm{http} / / w w w . e m e d i c i n e . c o m .2005$.
Isbagio, Hary 2001; Panduan Penatalaksanaan Osteoartritis Lutut dan Panggul; http//www.treatmentosteoartritis.ht m, 10 Agustus 2004.

Kalim, Handono 1996; Penyakit Sendi Degeneratif (Osteoartritis); Balai Penerbit KUI, Jakarta, hal. 76 - 84.

Kasjmir, Yoga 2003; Pengobatan Masa Depan Osteo Artritis; FK-UI RSUPN-CM, Jakarta, hal. 202205.

Kertia, Nyoman 5 Desember 2004; Nyeri pada Osteoartritis dan Rematoid Artritis; Simposium Pain, Yogyakarta, hal. 91-93.

Klaiman MD, Shrader JA, Danoff JV, et al 1998; Phonophoresis versus ultrasound in the treatment of common musculoskeletal conditions, Med Sci Sports Exerc,; 30(9):13491355

Kusumawati, K. 2003; Pengaruh Latihan Isotonik dengan En Tree terhadap Pengurangan Nyeri dan Perbaikan Kapasitas Fungsional pada Osteoartritis Lutut; UNDIP, Semarang, hal. 5 - 23.

Kusworini 2000; Masalah Penyakit Rhematik di Indonesia serta Upaya-Upaya Penanggulangannya; Horison, Jakarta, hal. $11-18$.

Mardiman, Sri 7-10 Maret 2001; Modulasi Nyeri dan Mekanisme Pengurangan Nyeri dengan Modalitas Fisioterapi; Profiso Sasana Husada; Pelatihan Pelaksanaan Fisioterapi Komprehensif Nyeri, RSOP, Surakarta.

Maurer, Brian T. and Stern, Alan G. and Kinnossian, Bruce and Cook, Karen D. and Schumacher, H. Ralph Oktober 1999; Jurnal 
Osteoarthritis of the Knee: Isokinetic Quadriceps Exercise Versus an Educational Intervention; in Arch Physical Medition Rehabilitation, volume 80, hal. 1293-1298.

Parjoto, Slamet 2-4 Oktober 2000; Asesmen Fisioterapi pada Osteoartritis Sendi Lutut; Titafi $\mathrm{XV}$, Semarang.

Poole, Robert M. and Blackburn, Tunner A, Jr. 1989; Dysfunction, Evaluation, and Treatment of the Knee; Donatelli, Robert and Wooden, Michael J.; Orthopaedic Physical Therapy; Churchill Livingstone Inc., New York,hal. 493-529.

Reksoprodjo, Soelarto Oktober 1990; Osteoarthritis Sendi Lutut; Majalah Fisioterapi Indonesia, edisi ke-5; IKAFI, Jakarta, hal. 7-19.

Sidharta, Priguna 1984; Sakit Neuromuskulo Skeletal dalam Praktik Umum; Dian Rakyat, Jakarta, hal. 181 - 185.

Van der Windt DA, van der Heijden GJ, van den Berg SG, et al 1999; Ultrasound therapy for musculoskeletal disorders: A systematic review Pian, 81(3):257-27 